\title{
Injections of corticotropin-releasing factor into the periaqueductal gray enhance Pavlovian fear conditioning
}

\author{
SHERALEE A. TERSHNER and FRED J. HELMSTETTER \\ University of Wisconsin, Milwaukee, Wisconsin
}

\begin{abstract}
Two experiments were conducted to determine if central administration of corticotropin-releasing factor (CRF) could influence the acquisition of a conditional fear response. In the first experiment, rats received either $\mathrm{CRF}(1.0 \mu \mathrm{g})$ or saline into the lateral ventricle prior to Pavlovian fear conditioning. Twenty-four hours later, freezing to the shock-associated context and the shock-associated discrete stimulus was measured. Subjects that received CRF prior to conditioning engaged in more freezing behavior to both types of stimuli than did the saline controls. In the second experiment, rats received either CRF $(0.4 \mu \mathrm{g})$ or saline into the ventral area of the midbrain periaqueductal gray (PAG) prior to fear conditioning. Direct application of CRF into the PAG also produced an enhancement in fear conditioning to both discrete and contextual stimuli. These results suggest that CRF is capable of modulating the acquisition of fear responses through a neural system that includes the PAG.
\end{abstract}

Corticotropin-releasing factor (CRF) is believed to play an important role in the expression of behavioral responses to stressful stimuli. In addition to its neuroendocrine effects, CRF has been shown to enhance stress responses by acting on specific receptors within the central nervous system (CNS) (De Souza, 1987).

In the presence of noxious or fear-provoking stimuli, intracerebroventricular (ICV) administration of CRF enhances freezing (Sherman \& Kalin, 1988), suppression of ongoing behavior (Cole \& Koob, 1988), and the acoustic startle response (Liang, Melia, Miserendino, et al., 1992; Swerdlow, Geyer, Vale \& Koob, 1986).

Most studies have examined the effects of CRF on the performance or expression of fear- or stress-induced behaviors. However, only a few studies have investigated whether CRF administration can influence the acquisition of fear-induced behavior during Pavlovian conditioning. There is some evidence to suggest that CRF may play a facilitatory role in the acquisition of passive avoidance tasks. Moderate doses of CRF have been shown to facilitate retention of an inhibitory avoidance task when tested 1 week posttraining. The same dose of CRF impaired retention of an appetitive learning task (Lee \& Sung, 1989). Similarly, injections of CRF into the locus coeruleus improve retention performance on a passive avoidance task, and this effect can be blocked by intrahippocampal pretreatment with 6-hydroxydopamine (Chen, Chiu, \& Lee, 1992). Direct application of CRF into the hippocampus has also been shown to improve passive avoidance learning (Lee, Hung, Lu, Chen, \& Chen, 1992).

This research was supported by PHS Grants DA07719 and MH49819 to F.J.H. Please address all correspondence to F. J. Helmstetter, Department of Psychology, University of Wisconsin, P.O. Box 413, Milwaukee,WI 53201 (e-mail: fjh@csd.uwm.edu).
Studies examining the behavioral effects of the CRF antagonist $\alpha$-helical $\mathrm{CRF}_{9-41}$ provide evidence that endogenous release of CRF into the CNS is involved in the performance of stress-related responses. ICV administration of $\alpha$-helical $\mathrm{CRF}_{9-41}$ attenuates shock-induced freezing (Kalin, Sherman, \& Takahashi, 1988) and stressrelated inhibition of performance in the elevated plusmaze test (Heinrichs, Pich, Miczek, Britton, \& Koob, 1992), and reverses the potentiation of acoustic startle produced by fear or CRF administration (Swerdlow, Britton, \& Koob, 1989).

The specific brain sites involved in the mediation of these behavioral responses enhanced by CRF have not been fully determined. CRF may have an effect on stressinduced behavioral responses through the amygdala. The importance of the amygdala in the coordination of behavioral, hormonal, and autonomic changes that occur during stressful situations has been well documented. Electrolytic and excitotoxic lesions of the amygdala have been shown to produce a general deficit in learned fear responses (Davis, 1992; LeDoux, 1992). More specifically, lesions of the central nucleus of the amygdala (CeA) prior to training attenuate blood pressure and freezing conditional responses to a CS for shock (Iwata, LeDoux, Meeley, Arnerie, \& Ries, 1986) and block potentiation of the acoustic startle reflex to both visual and auditory signals (Hitchcock \& Davis, 1987).

Although the CeA contains cells that use CRF, it has not been determined whether or not exogenous CRF produces an enhancement in fear responses by acting through $\mathrm{CeA}$. One study demonstrated that direct application of $\alpha$ helical $\mathrm{CRF}_{9-41}$ into the CeA dose-dependently reversed the heightened emotionality of socially defeated rats (Heinrichs et al., 1992). In another study, a similar dose of $\alpha$ helical $\mathrm{CRF}_{9-41}$ applied to the $\mathrm{CeA}$ was successful in re- 
ducing freezing behavior immediately following shock presentation and $24 \mathrm{~h}$ later when the rats were reexposed to the shock-associated environment (Swiergiel, Takahashi, \& Kalin, 1993). Others have reported that lesions of the CeA will block the enhancement of the acoustic startle response produced by ICV administration of CRF (Liang, Melia, Campeau, et al., 1992). However, direct injections of CRF into the CeA failed to produce the increase in acoustic startle response typically seen with ICV injections (Liang, Melia, Campeau, et al., 1992). These results suggest that although the amygdala is important for the enhancement of the acoustic startle response, neurons located within the $\mathrm{CeA}$ are not the primary site for CRF's ability to enhance fear responses when given ICV.

One efferent target of the $\mathrm{CeA}$ that is important for the expression of fear is the PAG. The central nucleus has moderate projections to the dorsolateral area of the PAG and more dense projections to the dorsomedial, lateral, and ventrolateral areas. In the more caudal regions of the PAG, the central nucleus projections are limited to the lateral and ventrolateral subdivisions (Bandler \& Shipley, 1994). Retrograde tracing techniques have also demonstrated that there are reciprocal projections between CeA and the PAG (Rizvi, Ennis, Behbehani, \& Shipley, 1991).

Although the amygdala is important in the organization of the behavioral and autonomic response to stress, the role of the PAG may be to more directly mediate the expression of these responses (Fanselow, 1991; Helmstetter \& Tershner, 1994). Lesion and pharmacological studies have shown that the expression of individual components of the fear response (hypertension, hypoalgesia, freezing, etc.) can be selectively elicited or blocked within defined areas of the PAG (Depaulis, Keay, \& Bandler, 1989; Helmstetter \& Landeira-Fernandez, 1990; Ledoux, Iwata, Cicchetti, \& Reis, 1988). Much of the defensive function of the PAG is presumably related to input from the amygdala, but very little is known about the neuropharmacology of these projections. There are terminals containing CRF located within the PAG that originate in the CeA (Gray \& Magnuson, 1992). It is not known whether these CRF neurons are involved in the mediation of fear responses.

The purpose of this study was to examine whether central administration of the CRF had an effect on the acquisition of Pavlovian fear conditioning. Recent research suggests that associations involving contextual versus discrete stimuli require separate neural substrates (e.g., Phillips \& LeDoux, 1992). The hippocampus is believed to be essential for the representation of contextual conditioned stimuli (CSs), whereas direct thalamoamygdaloid projections are sufficient for performance to a discrete auditory CS (LeDoux, 1993). On the basis of this anatomical distinction, it is possible that these substrates are differentially sensitive to pharmacological manipulations. Therefore, we sought to determine whether ICV administration of CRF would produce dissociable effects on the acquisition of fear responses to discrete or contextual conditional stimuli. In a second experiment, we examined a possible site of action for CRF's enhancing effect in the acquisition of conditional fear by directly injecting CRF into the ventrolateral region of the PAG.

\section{EXPERIMENT 1}

In a Pavlovian conditioning procedure where a discrete unimodal CS (e.g., a tone) predicts the occurrence of an aversive event (e.g., a footshock), the subject will learn to associate the footshock with both the discrete stimulus and the apparatus cues or context in which the stimulus and shock are presented. Recent studies have demonstrated that learning the association between a multimodal stimulus (e.g., a context) and footshock may require processes separate from those involved in learning the association between shock and a unimodal stimulus (Phillips \& Ledoux, 1992).

It has not been determined if CRF produces a general arousal or increase in fear that affects the processing of all stimuli equally or if CRF has a differential effect on the processing of contextual versus discrete stimuli. By measuring freezing to the discrete $\mathrm{CS}$ in a novel context and freezing to the training context in the absence of the discrete CS, it is possible to assess the effects of CRF on stimulus- and context-elicited freezing independently (Helmstetter \& Fanselow, 1989). In the first experiment, our aim was to determine if the ICV administration of CRF given prior to Pavlovian fear conditioning would differentially affect freezing to discrete versus contextual cues associated with the presentation of shock.

\section{Method}

Subjects. The subjects consisted of 16 male Long-Evans rats obtained from Harlan Sprague-Dawley, Inc. (Madison, WI) and weighing between 325 and $375 \mathrm{~g}$. All subjects were housed individually in stainless steel cages, where they had unlimited access to standard rat chow and water. The colony room was illuminated on a 14:10-h light:dark cycle and maintained at a constant temperature of $70^{\circ} \mathrm{F}$. All behavioral training and testing occurred during the light portion of the cycle.

Surgery. In preparation for surgery, the animals were anesthetized with ketamine $\mathrm{HCl}(100 \mathrm{mg} / \mathrm{kg}$ i.p.) followed by a supplemental injection of sodium pentobarbital ( $7.5 \mathrm{mg} / \mathrm{rat}$ i.p.). The animals were placed in a stereotaxic apparatus (Kopf Instruments, Tujunga, CA), where a 23-g stainless steel guide cannula (Plastics One, Roanoke, VA) was positioned above the right or left lateral ventricle and lowered using the following coordinates relative to bregma: +0.5 anterior, $\pm 1.5 \mathrm{~mm}$ lateral, and $-3.2 \mathrm{~mm}$ ventral from the surface of the skull (Paxinos \& Watson, 1986). The guide cannula was secured to the skull using screws and acrylic cement. A $30-\mathrm{g}$ obturator was inserted and screwed into the guide cannula. The rats were allowed to recover for 5 days before the experiment was continued. During these 5 days, the animals were handled extensively and habituated to cannula cleaning and manipulation while being held in a terry cloth towel. Upon completion of the experiment, $4 \mu \mathrm{l}$ of fast green dye was injected through the cannula and the rats were overdosed with an intraperitoneal injection of sodium pentobarbital ( $100 \mathrm{mg} / \mathrm{kg}$ ) and perfused transcardially with $0.9 \%$ saline, followed by $10 \%$ phosphate-buffered Formalin. The brains were removed from the skull and dissected to expose the cerebral ventricles. Only subjects with dye in all ventricles were included in the statistical analysis. 
Apparatus. Pavlovian conditioning took place in rodentobservation chambers $(28 \times 20.5 \times 21 \mathrm{~cm})$ that were positioned inside sound-attenuating chests. The side walls of the observation chambers were constructed of stainless steel and the back walls and doors were constructed of clear Plexiglas. A speaker $(9.5 \mathrm{~cm}$ diam, $8 \Omega, 4 \mathrm{~W}$ ), mounted on one of the side walls of each chamber, was calibrated to deliver a 74-dB presentation of white noise. White noise was produced through a Grason-Stadler noise generator (Model 901B) via a Med Associates relay interface panel. The floor of each observation chamber consisted of steel rods through which scrambled shock from a Grason-Stadler shock generator (Model 700) could be delivered. Each observation chamber was cleaned with a $1 \%$ acetic acid solution before and after each session. The sound-attenuating chests were illuminated by $7.5-\mathrm{W}$ white lightbulbs. Ventilation fans provided background noise at $68 \mathrm{~dB}$.

A second set of observation chambers were used during the testing phase. These chambers were modified to have visual, olfactory, and tactile features that were distinct from those of the observation chambers used for training. A piece of opaque Plexiglas was inserted into the chamber and positioned over the stainless steel grid floor. An additional piece of Plexiglas was used to form a triangular enclosure with the side walls at a $45^{\circ}$ angle. A speaker $(9.5 \mathrm{~cm}$ diam, $8 \Omega, 4 \mathrm{~W}$ ), calibrated to deliver a $74-\mathrm{dB}$ presentation of white noise, was mounted on one of the side walls of each chamber. White noise was produced through a Grason-Stadler noise generator (Model 901B) via a Med Associates relay interface panel. These novel chambers were cleaned with a $10 \%$ menthol solution prior to the testing session. These chambers were also housed in soundattenuation chests in a room separate from that used for training.

Prior to training, each subject received an ICV injection of either CRF or isotonic saline. CRF $(1 \mu \mathrm{g} / 4 \mu \mathrm{l})$ was dissolved in sterile isotonic saline and was infused using a $30-\mathrm{g}$ stainless steel cannula attached to a $20-\mathrm{cm}$ piece of PE-20 tubing. The injector was inserted into the guide cannula while the animal was held gently in a terry-cloth towel. The infusate was delivered over a 45 -sec period with a $10-\mu 1$ Hamilton syringe mounted in a Harvard infusion pump. Thirty seconds following the infusion, the injector was removed and replaced with the obturator.

Twenty minutes after injection, the rats were placed into the conditioning chambers. After $6 \mathrm{~min}$ had elapsed, the animals received a series of four 10 -sec presentations of white noise $(74 \mathrm{~dB})$, each followed by a single brief footshock $(1.6 \mathrm{~mA} / 1 \mathrm{sec})$. An intrashock interval of $100 \mathrm{sec}$ was used during the training session. After the shock presentations, each subject remained in the observational chamber for 6 min before being returned to the colony room. During training, the behavior of all subjects was recorded on video tape.

All animals were tested on 2 consecutive days. Freezing elicited by the context in which training had occurred was assessed separately from freezing elicited by the auditory stimulus. To measure context freezing, the animals were placed into the conditioning chambers and their behavior was videotaped for a 15 -min period. They did not receive discrete CS presentations or shock during this session. The animals were then returned to the colony room. To measure freezing to the auditory CS, the animals were placed in the novel chambers. After 6 min had elapsed, they received a single 5 -min presentation of the $\mathrm{CS}$ (white noise $/ 74 \mathrm{~dB}$ ). Five minutes after the white-noise presentation, the animals were returned to the colony room. Contextual and discrete CS freezing were recorded for each subject, and the order of testing was counterbalanced across subjects. The subjects remained in their home cages for $1 \mathrm{~h}$ between testing sessions.

Behavior during the training session was sampled from the videotapes once every $8 \mathrm{sec}$ for the 6 -min period prior to shock. Behavior was scored as either freezing or active. "Freezing" was defined as the absence of movement except for what was essential for respiration. "Active" was defined as all other nonfreezing be- havior. Immediately following each shock presentation, behavior was sampled every second to record the duration of the unconditional activity burst following shock (Fanselow, 1982). An activity burst was defined as the time period after shock preceding the occurrence of 2 consecutive seconds of freezing behavior. Following the four shock presentations, an 8-sec behavioral sampling schedule was resumed for the remainder of the session.

During each of the testing procedures on Day 2, behavior was scored as freezing or active. An 8-sec time-sampling interval was used to assess freezing during the 15 -min reexposure to the training context. Similarly, an 8-sec time-sampling interval was used to record behavior prior to, during, and after presentation of the CS in the novel context. The observer was always blind as to animals' group assignments.

\section{Results and Discussion}

Twelve animals were included in the data analysis; 6 of them had received ICV injections of CRF and 6 had received saline. Of the 4 animals that were dropped, 2 did not recover from surgery and were not tested and 2 had cannula placements outside of the lateral ventricle.

Freezing during the training session was subjected to a repeated measures analysis of variance (ANOVA). Freezing behavior was completely absent in both groups prior to their receiving the $\mathrm{CS}$ /shock pairings (data not shown). It is evident, from the absence of preshock freezing, that CRF infused into the cerebral ventricles does not produce nonspecific freezing behavior $20 \mathrm{~min}$ after administration. An analysis of the activity bursts following shock showed that rats treated with CRF displayed shorter periods of shock-evoked activity than did those treated with saline (see Figure 1). An ANOVA with shock presentation as a within-subject variable yielded a significant main effect for drug treatment $[F(1,10)=8.827, p<.05]$ without a significant effect for shock presentation $[F(3,30)=$ $2.887, p>.05]$ or a shock $\times$ drug interaction $[F(3,30)=$ $2.551, p>.05]$. Thus, while there was no difference in the amount of freezing behavior prior to shock presentations, CRF-treated animals tended to begin freezing after each CS-shock pairing sooner than did the saline controls. Although both groups showed high levels of freezing during the period following CS-shock pairings, these values (CRF: $n=6, M=67.9$, SEM $=8.46$; saline: $n=6, M=$ $50.57, S E M=12.05$ ) were not statistically different $[F(1,10)=1.154, p>.05]$.

In the analysis of freezing in the training context, the percentage of time spent freezing was averaged for each minute of the 15 -min testing session. A repeated measures ANOVA with time as a within-subject variable was performed on context-elicited freezing data for each test day. As shown in Figure 2, there was a significant increase in context-elicited freezing on Test Day 1 in the animals that received CRF prior to shock as compared with the control group. There was a significant main effect for drug treatment $[F(1,10)=15.82, p<.01]$ and for time $[F(14,140)=2.662, p<.01]$ but no significant interaction $[F(14,40)=1.173, p>.05]$. The enhancement in context freezing was still present on Test Day 2. The CRF-treated animals spent $32 \%$ of the test period freezing, while the saline-treated animals froze only ap- 
proximately $13 \%$ of the time. The main effect for drug treatment was statistically significant $[F(1,10)=5.30$, $p<.05]$.

In the analysis of freezing elicited by the discrete CS, the percentage of time spent freezing was averaged for each minute of the 16-min test session. The mean percentages during the three phases of this test session (pre$\mathrm{CS}, \mathrm{CS}$, and post-CS) are displayed in Figure 3. ANOVAs with time as a within-subject variable were performed on freezing within each of the phases of the test session. Prior to the discrete CS presentation, the groups did not differ in the amount of freezing on either Day 1 or Day 2. Animals that received CRF during training froze significantly more within the discrete CS period than did those receiving saline. There was a significant main effect for drug $[F(1,10)=10.30, p<.01]$ but no effect for time $[F(4,40)=1.873, p>.05]$ and no drug $\times$ time interaction $(F<1.0)$. On Day 2 of testing, the CRF-treated animals still showed higher levels of freezing during the discrete CS period than did the saline-treated animals, although this result was not statistically significant $(F<$ 1.0). Similarly, the CRF-treated animals appeared to be freezing more during the post-CS periods for both test days, although freezing levels between the groups did not differ significantly on either of the test days [Day 1, $F(1,10)=1.639, p>.05$; Day $2, F<1.0]$.

ICV administration of CRF does not appear to produce freezing behavior 20 min after injections but is able to modulate the acquisition of conditional fear responses as measured by freezing to contextual and discrete CSs. These data failed to support any differential effects CRF may have had on the processing of unimodal versus multimodal stimuli during acquisition.

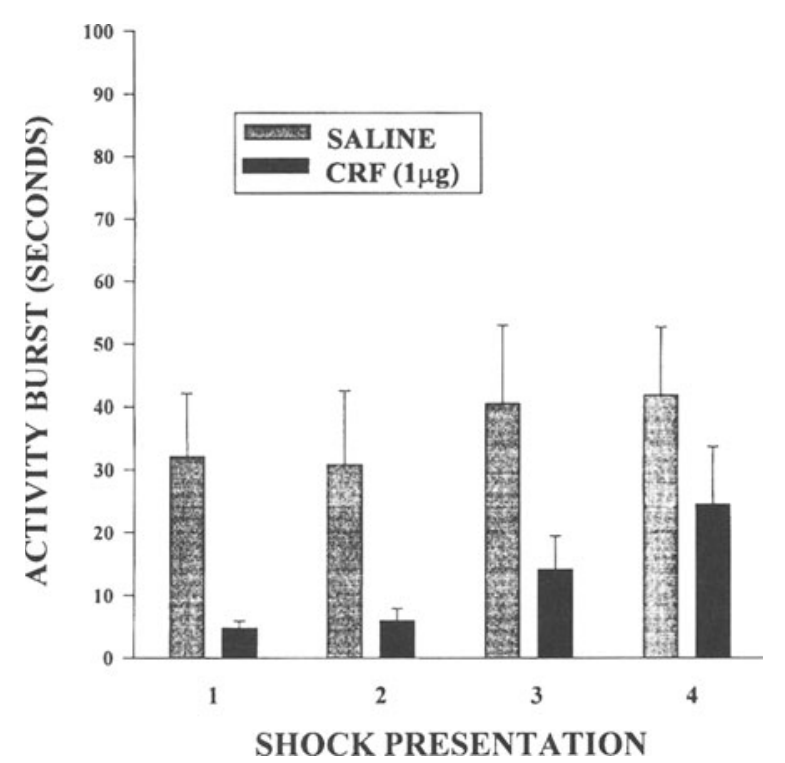

Figure 1. Mean activity-burst duration for rats that received CRF or saline ICV. Length of activity burst is presented for each shock presentation. Rats that received CRF showed a significant decrease in activity burst. Vertical bars indicate the standard error of the mean.

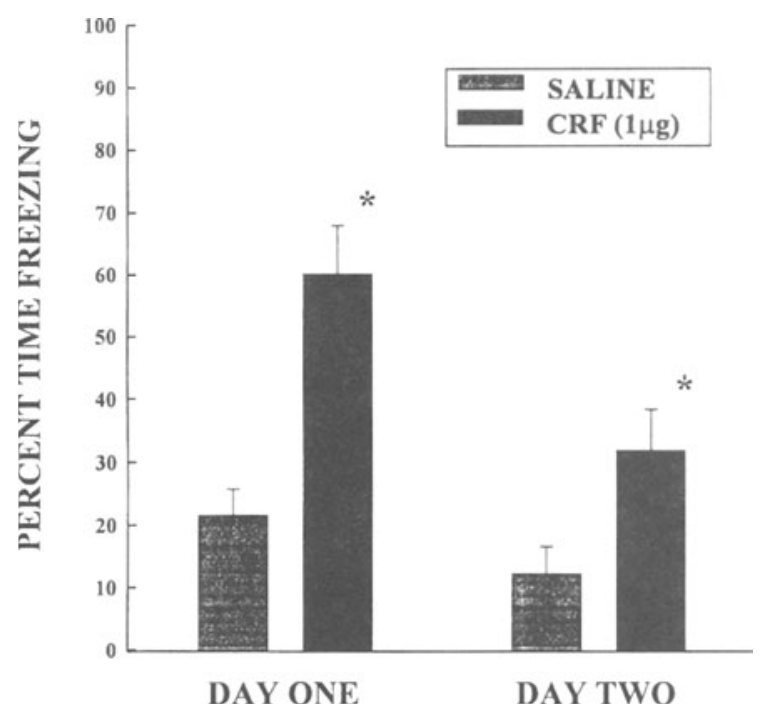

Figure 2. Mean values for the percentage of time engaged in freezing upon reexposure to the shock-associated context. Rats that received CRF into the lateral ventricles spent significantly more time freezing than did the saline-treated rats. ${ }^{*} p<.05$.

\section{EXPERIMENT 2}

The data from Experiment 1 are in agreement with the general idea that central administration of CRF has modulatory effects on fear- or stress-induced behaviors. It is still necessary to examine specific brain areas that may be involved in the mediation of these behavioral responses as enhanced by the CRF. As mentioned above, there is an abundance of evidence to support the idea that a neural system that includes the $\mathrm{CeA}$ and the ventral PAG is involved in the mediation of fear responses, including freezing. Therefore it is possible that CRF normally functions in modulating fear conditioning through a connection between the amygdala and PAG.

The purpose of Experiment 2 was to determine if sitespecific injections of CRF into the ventral PAG would have an effect on the acquisition of contextual or discrete stimulus-elicited freezing that was similar to the effects produced by ICV injections.

\section{Method}

Subjects. The subjects consisted of 16 male Long-Evans rats, obtained from Harlan Sprague-Dawley, Inc. (Madison, WI) and weighing between 325 and $375 \mathrm{~g}$. Housing and care of the animals were the same as in Experiment 1.

Surgery. The general surgical procedures and cannula maintenance were the same as those in Experiment 1. A 26-g stainless steel cannula was unilaterally positioned in the right or left side of the ventral PAG, using the following coordinates: $-7.8 \mathrm{~mm}$ from bregma, $\pm 0.8 \mathrm{~mm}$ lateral, and $-6.0 \mathrm{~mm}$ ventral from the surface of the skull (Paxinos \& Watson, 1986). Upon completion of the experiment, the rats were overdosed with an intraperitoneal injection of sodium pentobarbital $(100 \mathrm{mg} / \mathrm{kg})$ and perfused transcardially with $0.9 \%$ saline, followed by $10 \%$ phosphate buffered Formalin. Following decapitation, the heads were left in buffered Formalin for $24 \mathrm{~h}$. The brains were then soaked in sucrose/Formalin for an additional $24 \mathrm{~h}$. To verify cannula placements, the brains were 


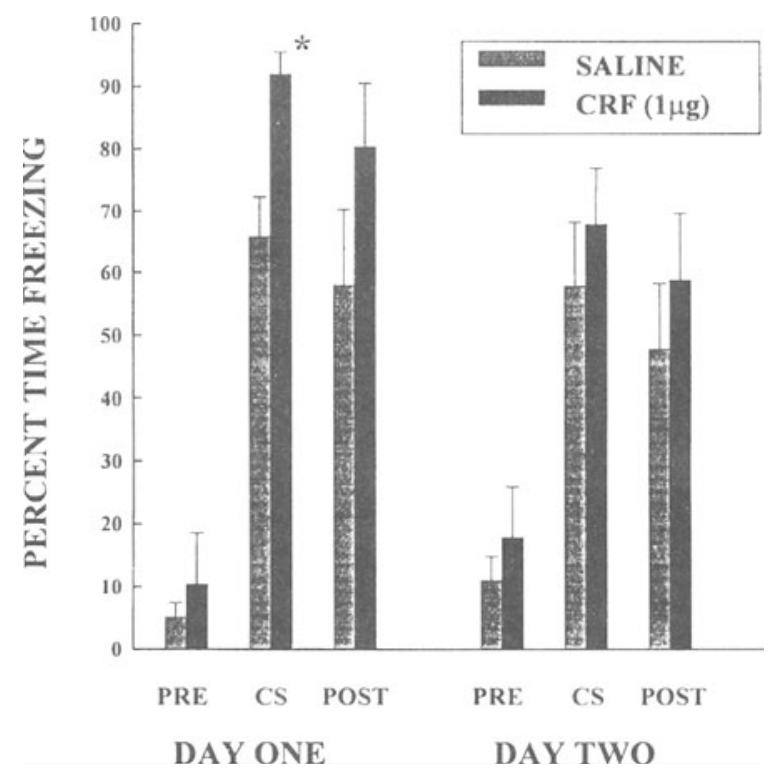

Figure 3. Mean values of the percentage of time engaged in freezing before, during, and after presentation of the auditory $C S$ in the novel context. Rats that received $\mathrm{CRF}$ into the lateral ventricles froze more during the CS presentation than did the saline controls. ${ }^{*} p<.05$.

sliced into coronal sections $(40 \mu \mathrm{m})$, mounted on slides, and stained using cresyl violet. Only subjects with cannula placements within the ventral portion of the PAG and the neighboring dorsal raphe nucleus, as defined by Paxinos and Watson (1986), were included in the analyses.

Apparatus and Procedure. CRF $(0.8 \mu \mathrm{g} / \mu \mathrm{l})$, dissolved in sterile isotonic saline, was infused into the guide cannula using an injector constructed from a $33-\mathrm{g}$ stainless steel internal cannula attached to a $20-\mathrm{cm}$ piece of PE-20 tubing. The injector was inserted into the guide cannula while the animal was gently held in a terrycloth towel. The volume of $0.5 \mu \mathrm{l}$ of infusate was delivered over a $30-\mathrm{sec}$ period with the use of a $1.0-\mu 1$ Hamilton glass syringe mounted on a Harvard infusion pump. Each animal assigned to the treatment group received a total of $0.4 \mathrm{mg}$ of CRF. The control group received an equal volume of isotonic saline. Thirty scconds following administration, the injector was removed and replaced by the obturator. Otherwise, the procedure for the training and testing sessions was identical to that in Experiment 1.

\section{Results and Discussion}

Fourteen rats were included in the analyses; 6 of them received saline and 8 received CRF. Two rats failed to recover from surgery and were not tested. Of the subjects included in the analyses, $7 \mathrm{CRF}$ rats had cannula placements located within the ventrolateral PAG, and 1 subject's cannula was located within the dorsal raphe nucleus and bordered on the PAG (see Figure 4). Along the rostral/caudal axis, all cannula placements were located at the level of the dorsal raphe nucleus.

Freezing behavior was scored and analyzed as in Experiment 1 . Neither group displayed any freezing behavior prior to the CS-shock pairings during the training session. This demonstrates that direct infusion of CRF into the ventral PAG does not produce freezing by itself at $20 \mathrm{~min}$ after injection. CRF-treated rats showed a significant decrease in activity burst duration as compared with saline-treated rats (see Figure 5). A significant main effect was found for drug treatment $[F(1,12)=8.196$, $p<.05]$ but not for shock presentation $[F(3,39)=1.638$, $p>.05$ ]; there was no drug $\times$ shock interaction $(F<1.0)$. Levels of freezing were high for both groups during the postshock period (CRF: $n=7, M=63.54, S E M=11.24$; saline: $n=8, M=78.8, S E M=7.49)$, although the groups were not significantly different $[F(1,12)=1.160, p>.05]$. This decrease in activity-burst duration in rats that received CRF into the ventral PAG replicates the findings in Experiment 1.

In the analysis of context-elicited freezing, it is evident that direct injections of CRF into the ventral PAG effectively increased freezing to the shock-associated context on Day 1 (see Figure 6). A repeated measures ANOVA showed a main effect for drug treatment $[F(1,12)=10.709$, $p<.01]$ but failed to report a significant effect for time $(F<1.0)$ or a drug $\times$ time interaction $(F<1.0)$. On average, the CRF-treated rats engaged in freezing behavior

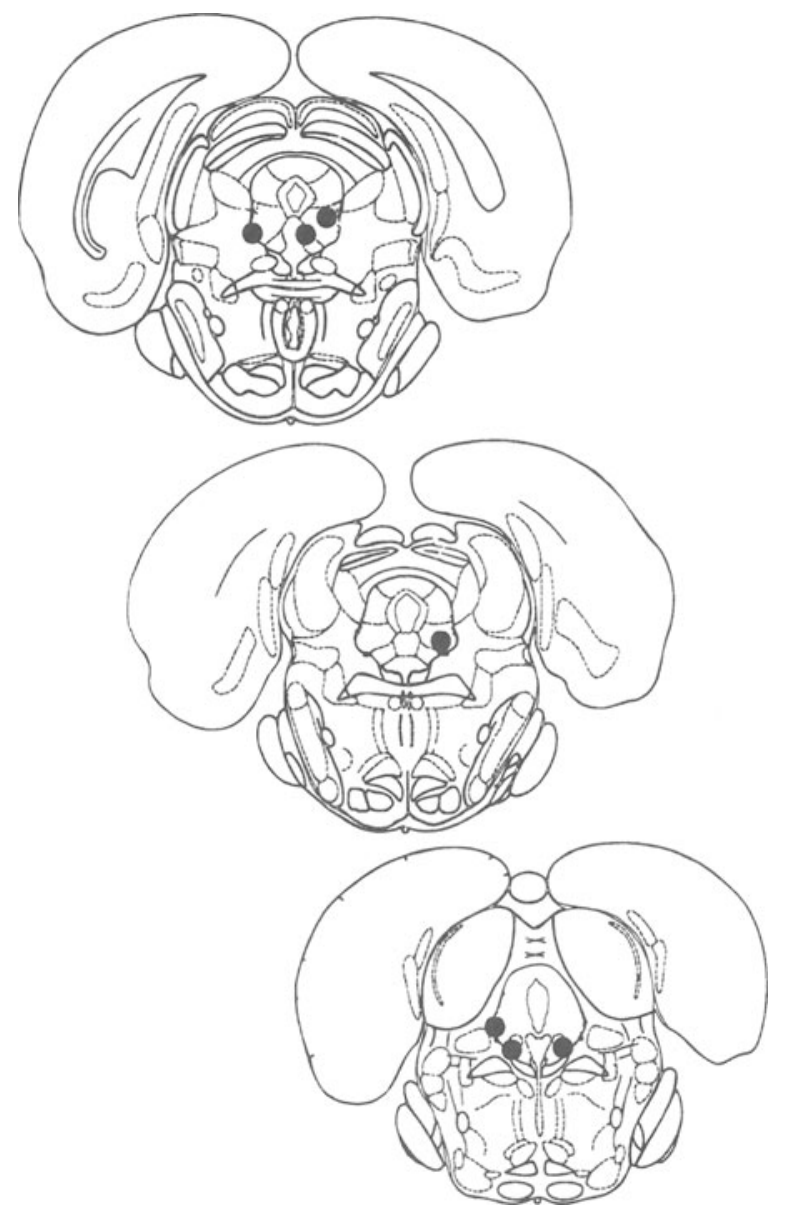

Figure 4. Injection sites for CRF-treated rats included in the analysis for Experiment 2. Only animals with cannulae placements in or bordering on the ventrolateral PAG were included. 
during $45 \%$ of the $15-\mathrm{min}$ test session. Saline-treated rats froze an average of $18 \%$ of the session. On Test Day 2, the CRF-treated rats continued to freeze more to the shockassociated context $(23 \%)$ than did the saline controls $(12 \%)$, but this difference failed to reach statistical significance $[F(1,12)=2.847, p>.05]$.

The mean percentage of freezing elicited by the discrete $\mathrm{CS}$ for both test days is presented in Figure 7. As in Experiment 1, the level of pre-CS freezing was the same for the CRF-injected and the saline-injected rats on both test days. CRF-treated rats froze more than the salinetreated rats during the 5-min discrete CS presentation on Test Day 1. Although the main effect for drug treatment was statistically marginal $[F(1,12)=3.445, p<.08]$, there was a significant effect for time $[F(4,48)=5.163, p<$ $.01]$ and a drug $\times$ time interaction $[F(4,48)=3.391, p<$ $.05]$. The enhanced freezing during the discrete CS was still present in the CRF group on Test Day 2. A repeated measures ANOVA revealed a significant main effect for drug treatment $[F(1,12)=5.073, p<.05]$ and a significant effect for time $[F(4,48)=5.116, p<.01]$ but no drug $\times$ time interaction $(F<1.0)$. The CRF-treated rats showed higher post-CS freezing than did the saline-treated rats on Test Day 1 . There was a main effect for drug treatment $[F(1,12)=6.031, p<.05]$ and for time $[F(4,48)=6.862$, $p<.01]$ but no drug $\times$ time interaction $(F<1.0)$. This difference was not present on Test Day $2(F<1.0)$.

To test whether there might be differential effects of right versus left cannula placement within the PAG, subsequent post hoc $t$ tests were performed. Multiple $t$ tests showed that there were no significant effects for lateralization within the saline group for context-elicited freez-

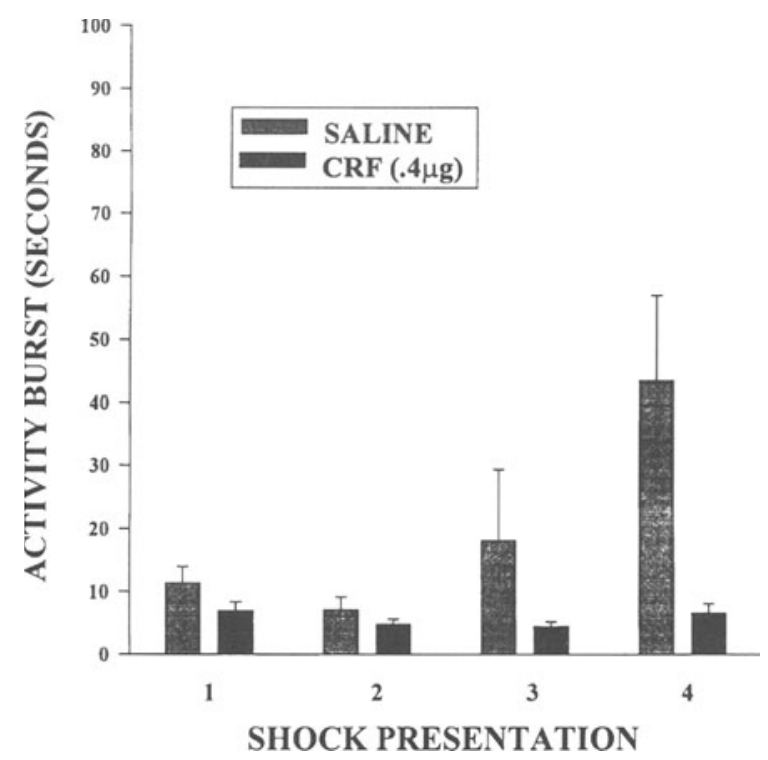

Figure 5. Mean activity bursts for rats that received CRF or saline into the PAG. Length of activity burst is presented for each shock presentation. Rats that received CRF showed a significant decrease in activity burst.

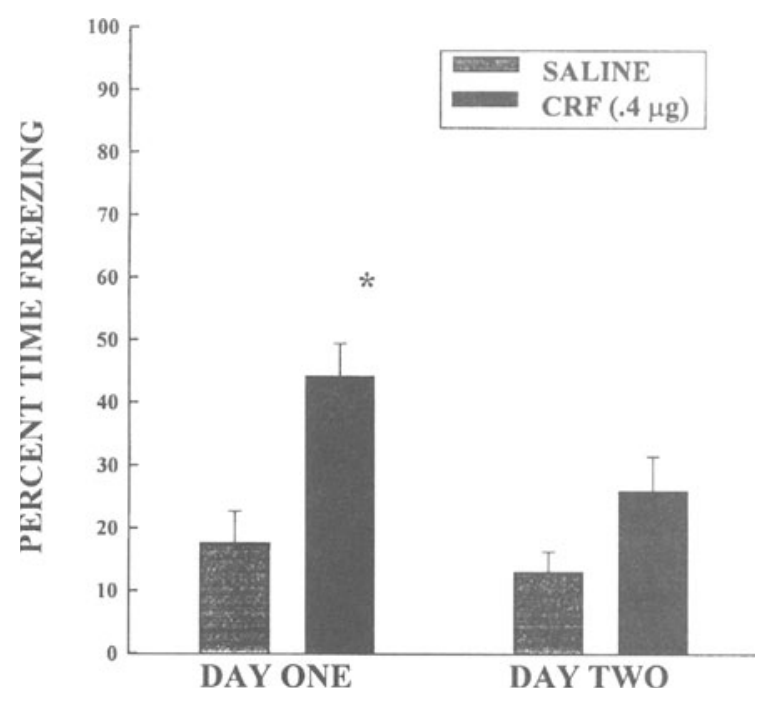

Figure 6. Mean values for the percentage of time engaged in freezing upon reexposure to the shock-associated context. Rats that received CRF into the PAG spent significantly more time freezing than did the saline-treated rats. ${ }^{*} p<.05$.

ing on either test day [Test Day $1, t(4)=1.274, p>.05$; Test Day $2, t(4)=.610, p>.05]$. Similarly, there were no significant effects for lateralization within the saline group for discrete-CS-elicited freezing on either test day [Test Day $1, t(4)=-0.410, p>.05$; Test Day $2, t(4)=$ $-0.691, p>.05]$. A similar pattern of results was found in the CRF-treated animals. No significant effects were found for lateralization within the CRF group for contextelicited freezing on either test day [Test Day $1, t(6)=$ $.458, p>.05$; Test Day 2, $t(6)=1.434, p>.05]$. In addition, there were no effects for lateralization within the CRF group for discrete-CS-elicited freezing on either test day [Test Day $1, t(6)=-0.005, p>.05$; Test Day 2, $t(6)=.442, p>.05]$.

The analysis of Experiment 2 suggests that CRF injected directly into the ventral PAG enhances freezing to a discrete CS that had been previously associated with the administration of footshock and to the context in which the CS and the footshock were presented.

Since the PAG is located around the cerebral aqueduct, it is important to be sure that the results of Experiment 2 are due to CRF's acting in the PAG and not to the peptide's diffusing into the ventricular system and acting at another site. Examination of the injection sites suggests a relationship between cannula placements within the PAG and amount of enhanced freezing. Although the number of rats used in the experiment is too small for a complete description of this relationship, the magnitude of CRF's effect on freezing was larger when the injections were made in the caudal regions of the PAG. If the effect was due primarily to diffusion, then any site at an equal distance from the aqueduct should have had similar effects on acquisition. In addition, other recent studies conducted in our laboratory support the idea that 


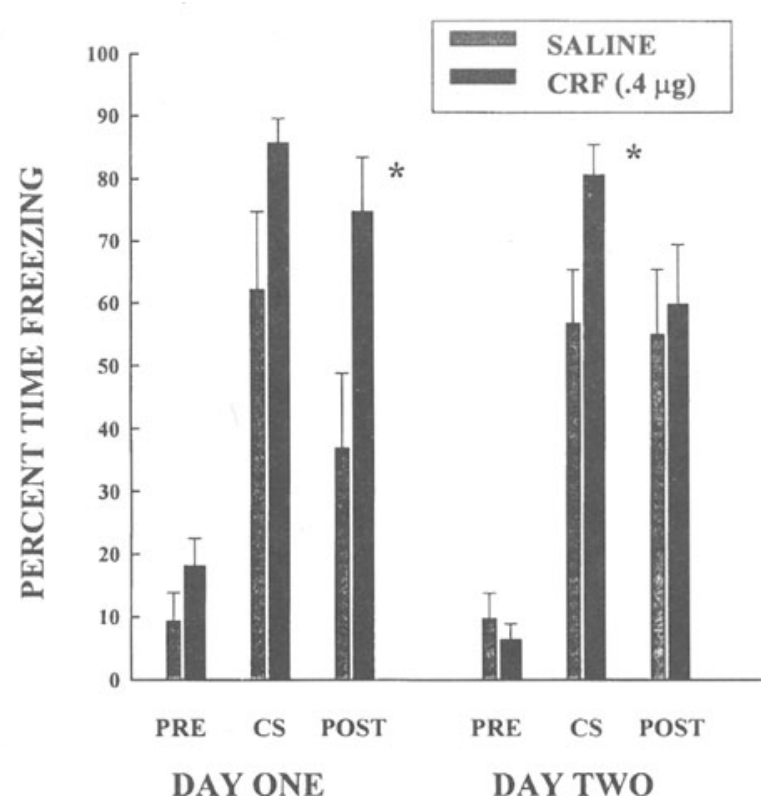

Figure 7. Mean values of the percentage of time engaged in freezing before, during, and after the $C S$ presentation in the novel context. Rats that received CRF into the PAG froze more during the CS presentation than did the saline controls. ${ }^{*} p<.05$.

CRF is interacting directly with receptors in the PAG (Tershner \& Helmstetter, 1994).

\section{GENERAL DISCUSSION}

The results of Experiment 1 indicate that CRF enhances acquisition of conditional fear when applied directly into the ventricular system. The CRF-treated animals showed an increase in freezing when compared with the salinetreated animals independent of the nature of the conditional stimuli. Experiment 2 yielded similar results. Rats receiving CRF into the PAG showed higher levels of freezing $24 \mathrm{~h}$ after training to both the discrete CS and the shock-associated context. These results lend support to the idea that the PAG may be involved in CRF enhancement of fear conditioning. An absence of freezing behavior $20 \mathrm{~min}$ after CRF administration is in agreement with other studies that have shown that central administration of CRF does not produce fear-related behaviors but is able to enhance existing fear states (Britton, Koob, Rivier, \& Vale, 1982). Since CRF was administered only during training, the change in freezing behavior observed on the subsequent test days could not be attributed to the peptides altering the performance of this response. It appears that CRF may play a role in the facilitation of learning of significant stimuli.

CRF did not have differential effects on the acquisition of conditional fear responses involving discrete versus contextual stimuli, suggesting that CRF may be enhancing fear conditioning by affecting general attentional or arousal mechanisms involved in learning. It has been proposed that increased attention or arousal facilitates learn- ing by making information processing more efficient (Squire, 1987), and there is some evidence that CRF enhances retention performance of aversively motivated tasks by the activation of noradrenergic cells believed to be involved in brainstem modulation of arousal (Chen et al., 1992). CRF may also be enhancing learning by increasing the salience of the predictive stimuli (discrete $\mathrm{CS}$ or context). Increasing the salience of a conditional stimulus has been shown to strengthen associative learning (Kamin, 1965).

Since the PAG is involved in pain modulation as well as other defensive behaviors, CRF may also alter the functional intensity of the unconditioned stimulus. Some support for this alternative may be found by reviewing the activity burst data in Figure 5. The CRF rats displayed shorter activity bursts than the saline rats, which may be an indication that they are hypoalgesic. In theory, a decrease in activity bursts can be accounted for by an increase in analgesia produced by fear (Fanselow, 1991). It appears that the increase in fear during acquisition produced by CRF administration may have simultaneously produced hypoalgesia. While others have failed to find hypoalgesia with central administration of CRF (Sherman \& Kalin, 1986), recent data from our laboratory have shown that CRF injected into the ventrolateral PAG produces tailflick inhibition in anesthetized rats (Tershner \& Helmstetter, 1994). The relationship between magnitude of tailflick inhibition and injection sites within the PAG is similar to the relationship observed in the present enhancement of fear conditioning. Injection sites in the caudal regions of the PAG were more effective in producing tailflick inhibition. However, if CRF's effect on the activity burst was due to hypoalgesia, one would also expect a decrease in freezing $24 \mathrm{~h}$ after shock instead of the increase shown in these experiments (e.g., Helmstetter \& Fanselow, 1987). CRF's ability to facilitate fear conditioning may therefore be more closely related to its anxiogenic properties than to potential changes in nociception.

While most experimental attention has been focused on the behavioral functions of the PAG, with emphasis on its role in the coordination and expression of defensive behavior patterns (Bandler \& Shipley, 1994; Fanselow, 1991; Helmstetter \& Tershner, 1994), the present data suggest that this region may also play a role in the acquisition of aversive Pavlovian conditioning. Although these two experiments do not present a complete picture of the PAG's potential role in learning aversive Pavlovian CRs, the data are consistent with our proposal that projections from the CeA to the PAG that contain CRF are important.

\section{REFERENCES}

Bandler, R., \& Shipley, M. T. (1994). Columnar organization in the midbrain periaqueductal gray: Modules for emotional expression. Trends in Neurosciences, 17, 379-389.

Britton, D. R., Koob, G. F., Rivier, J., \& Vale, W. (1982). Intraventricular corticotropin-releasing factor enhance behavioral effects of novelty. Life Sciences, 31, 363-367.

Chen, M. F., Chiu, T. H., \& LeE, E. H. (1992). Noradrenergic media- 
tion of the memory-enhancing effect of corticotropin-releasing factor in the locus coeruleus of rats. Psychoneuroendocrinology, 17(2-3), 113-124.

Cole, B. J., \& КоOB, G. F. (1988). Propranolol antagonizes the enhanced conditional fear produced by corticotropin-releasing factor. Journal of Pharmacology \& Experimental Therapeutics, 247, 902910.

Davis, M. (1992). The role of the amygdala in conditioned fear. In J. P. Aggleton (Ed.), The amygdala: Neurobiological aspects of emotion, memory, and mental dysfunction (pp. 255-306). New York: WileyLiss.

Depaulis, A., Keay, K. A., \& BAndler, R. (1989). Longitudinal neuronal organization of defensive reactions in the midbrain periaqueductal gray region of the rat. Experimental Brain Research, 90, 307. 318.

DE SOUZA, E. B. (1987). Corticotropin-releasing factor receptors in the rat central nervous system: Characteristics and regional distribution. Journal of Neuroscience, 7, 88-100.

FANSELOW, M. S. (1991). The midbrain periaqueductal gray as a coordinator of action in response to fear and anxiety. In A. Depaulis \& R. Bandler (Eds.), The midbrain periaqueductal gray matter (pp. 151173). New York: Plenum.

Gray, T. S., \& MAGnuson, D. J. (1992). Peptide immunoreactive neurons in the amygdala and the bed nucleus of the stria terminalis project to the midbrain central gray in the rat. Peptides, 13, 451-460.

HeinRichs, S. C., Pich, E. M., MiczeK, K. A., Britton, K. T., \& KoOB, G. F. (1992). Corticotropin releasing factor antagonist reduces emotionality in socially defeated rats via direct neurotropic action. Brain Research, 581, 190-197.

HelmSTETTER, F. J., \& FANSELOW, M. S. (1987). Effects of naltrexone on learning and performance of conditional fear-induced freezing and opioid analgesia. Physiology \& Behavior, 39, 501-505.

Helmstetter, F. J., \& Fanselow, M. S. (1989). Differential secondorder aversive conditioning using contextual stimuli. Animal Learning \& Behavior, 17, 205-212.

Helmstetter, F. J;; \& Landiera-Fernandez, J. (1990). Conditional hypoalgesia is attenuated by naltrexone applied to the PAG. Brain Research, 537, 88-92.

Helmstetter, F. J., \& Tershner, S. A. (1994). Lesions of the periaqueductal gray and rostral ventromedial medulla disrupt antinociceptive but not cardiovascular aversive conditional responses. Journal of Neuroscience, 14, 7099-7108.

Hiтcнсоск, J. M., \& Davis, M. (1987). Fear potentiated startle using an auditory conditioned stimulus: Effect of lesions of the amygdala. Physiology \& Behavior, 39, 403-408.

Iwata, J., LeDoux, J. E., Meeley, M. P., Arnerie, S., \& Ries, D. J. (1986). Intrinsic neurons in the amygdaloid field projected to by the medial geniculate body mediate emotional responses conditioned to acoustic stimuli. Brain Research, 371, 395-399.

Kalin, N. H., Sherman, J. E., \& TaKahashi, L. K. (1988). Antagonism of endogenous $\mathrm{CRH}$ systems attenuates stress-induced freezing behavior in rats. Brain Research, 457, 130-135.

KAMIN, L. J. (1965). Temporal and intensity characteristics of the conditioned stimulus. In W. F. Prokasy (Ed.), Classical conditioning: A symposium (pp. 118-147). New York: Appleton-Century-Crofts.

LEDOUX, J. E. (1992). Brain mechanisms of emotion and emotional learning. Current Opinions in Neurobiology, 2, 191-198.
LeDoux, J. E. (1993). Emotional memory systems in the brain. Behavioral Brain Research, 58, 69-79.

Ledoux, J. E., Iwata, J., Cicchetti, P., \& Reis, D. J. (1988). Different projections of the central amygdaloid nucleus mediate autonomic and behavioral correlates of conditional fear. Journal of Neuroscience, 8, 2517-2529.

Lee, E. H., Hung, H. C., Lu, K. T., Chen, W. H., \& Chen, H. Y. (1992). Protein synthesis in the hippocampus associated with memory facilitation by corticotropin releasing factor in rats. Peptides, 13, 927 937.

LEE, E.H., \& SUNG, Y. J. (1989). Differential influences of corticotropin releasing factor on memory retention of aversive learning and appetitive learning in rats. Behavioral \& Neural Biology, 52, 285295.

Liang, K. C., Melia, K. R., Campeau, S., Falls, W. A., Miserendino, J. D., \& DAVIS, M. (1992). Corticotropin-releasing factor: Long-lasting facilitation of the acoustic startle reflex. Journal of Neuroscience, 12, 2313-2320.

liang, K. C., Melia, K. R., Miserendino, M. J. D., Falls, W. A., Campeau, S., \& Davis, M. (1992). Corticotropin-releasing factor facilitation of the acoustic startle reflex. Journal of Neuroscience, 12 , 2303-2312.

Paxinos, G., \& Watson, C. (1986). The rat brain in stereotaxic coordinates. New York: Academic Press.

Phillips, R. G., \& LeDoux, J. E. (1992). Differential contribution of amygdala and hippocampus to cued and contextual fear conditioning. Behavioral Neuroscience, 106, 274-275.

Rizvi, T. A., Ennis, M., Behbehani, M. M., \& Shipley, M. T. (1991). Connections between the central nucleus of the amygdala and the midbrain periaqueductal gray: Topography and reciprocity. Journal of Comparative Neurology, 303, 1121-1131.

Sherman, J. E., \& Kalin, N. H. (1986). ICV-CRH potently affects behavior without altering antinociceptive responding. Life Sciences, 39, 433-441.

Sherman, J. E., \& Kalin, N. H. (1988). ICV-CRH alters stress-induced freezing behavior without affecting pain sensitivity. Pharmacology, Biochemistry \& Behavior, 30, 801-807.

SQUiRe, L. R. (1987). Memory and brain. New York: Oxford University Press.

SWERDLOW, N.R., BRitTon, K.T., \& KoOB, G. F. (1989). Potentiation of acoustic startle by corticotropin-releasing factor (CRF) and by fear are both reversed by $\alpha$-helical CRF (9-41). Neuropsychopharmacology, 2, 285-292.

Swerdlow, N. R., Geyer, M. A., Vale, W. W., \& Koob, G. F. (1986). Corticotropin releasing factor potentiated acoustic startle in rats, blocked by chlordiazepoxide. Psychopharmacology, 88, 147-152.

Swiergiel, A. H., Takahashi, L. K., \& Kalin, N. H. (1993). Attenuation of stress-induced behavior by antagonism of corticotropin releasing factor in the central amygdala of the rat. Brain Research, 623, 229-234.

Tershner, S. A., \& Helmstetter, F. J. (1994). Injections of corticotropin releasing factor into the periaqueductal gray produce antinociception. Neuroscience Abstracts, 20, 766.

(Manuscript received July 24, 1995; revision accepted for publication October 12, 1995.) 